\title{
USING GOOGLE ANALYTICS TO EVALUATE THE IMPACT OF THE CYBERTRAINING PROJECT.
}

Conor Mc Guckin and Niall Crowley

School of Education, Trinity College Dublin, Dublin 2, Ireland

Header: Google Analytics and CyberTraining

Editorial Correspondence:

Conor Mc Guckin, School of Education, Trinity College Dublin, Dublin 2, Ireland.

Telephone: 00 (353) 871300177, Fax: 00 (353) 16777238, E-mail: conor.mcguckin@tcd.ie

Reprint requests should be directed to:

Conor Mc Guckin

School of Education

Trinity College Dublin

Dublin 2

Ireland

E-mail: conor.mcguckin@tcd.ie 


\begin{abstract}
A focus on results and impact should be at the heart of every project's approach to research and dissemination. This article discusses the potential of Google Analytics (GA: http://google.com/analytics) as an effective resource for measuring the impact of academic research output and understanding the geo-demographics of users of specific Web 2.0 content (e.g., intervention and prevention materials, health promotion and advice). This paper presents the results of GA analyses as a resource used in measuring the impact of the EUfunded CyberTraining project which provided a well-grounded, research-based training manual on cyberbullying for trainers through the medium of a web-based eBook (http://www.cybertraining-project.org). The training manual includes review information on cyberbullying, its nature and extent across Europe, analyses of current projects and provides resources for trainers working with the target groups of pupils, parents, teachers, and other professionals. Results illustrate the promise of GA as an effective tool for measuring the impact of academic research and project output with real potential for tracking and understanding intra- and inter-country regional variations in the uptake of prevention and intervention materials, thus enabling precision focusing of attention to those regions.
\end{abstract}

Keywords: Cyberbullying, Google Analytics, CyberTraining, Bully, Victim 


\section{INTRODUCTION}

Bully / victim problems among school pupils is an international problem ${ }^{1}$. A robust crossnational knowledge base of intervention and prevention programmes in the area has been developed and illustrated ${ }^{2,3}$. Coupled with this increased knowledge regarding 'traditional' bully / victim problems (also referred to as 'face-to-face' or ' $\mathrm{f} 2 \mathrm{f}$ ' bullying ${ }^{4}$ ), we are also at the stage where we are increasing our knowledge of new, more contemporary, forms of such problems, such as cyberbullying $4,5,6,7,8,9,10$. However, unlike f2f bully / victim problems, we have scant knowledge of how to counter the insidious effects of cyberbullying.

The recently completed CyberTraining project (funded by the EU Lifelong Learning Programme: [Project No.142237-LLP-1-2008-1-DE-LEONARDO-LMP] http://cybertrainingproject.org) has provided a well-grounded, research-based training manual on cyberbullying for trainers. The manual was based upon the outcomes of: (i) a 'needs assessment' conducted with trainers across partner countries, (Germany, Ireland Portugal, Spain, United Kingdom, and Bulgaria), (ii) the perspectives solicited from subject experts via the Delphi method, and (iii) trans-national analyses of the situation in partner countries, in terms of research efforts and interventions.

The manual includes background information on cyberbullying, its nature and extent in Europe, current projects, initiatives and approaches tackling the cyberbullying problem, best practice Europe-wide, as well as practical guidance and resources for trainers working with the target groups of: (i) pupils, (ii) parents, and (iii) teachers, schools, and other professionals. The manual concludes with a comprehensive compilation of references, links, and other resources for trainers. The manual was published online in Autumn 2010 in the user-friendly format of an eBook and is available in English, Spanish, French, German, Portuguese, and Bulgarian versions (see also ${ }^{11}$ for a presentation of key reports from the 
project partner countries as well as country reports from Central and Eastern Europe, the Mediterranean countries, Scandinavia, Australasia, and the United States).

\section{Effective Project Dissemination and Measuring Project Impact}

A project is only as useful as the scope and impact of its dissemination. Researchers and practitioners focus predominantly on traditional routes of dissemination, such as; conference presentations, peer-reviewed journal articles, monographs, book chapters, and static web content. However, in a climate of 'evidence-informed practice', commissioners of research and intervention / prevention programs are seeking a more robust analysis of dissemination activity - one that does not simply follow the 'traditional' top-down approach. Rather, what is increasingly required is an approach that allows analysis of 'impact' and usability by endusers. Considering that much research output and the content of intervention / prevention programs are made available via the Internet and Web 2.0 technologies, it is incumbent upon researchers and practitioners to understand how and where the information is been accessed. For example, whilst most governments have online information regarding bully / victim prevention and helpful resources, the online monitoring of web-traffic pertaining to those materials would give an early indication of 'hot' regional activity, thus enabling the easy identification of geographical areas that could benefit from rapid communication and dissemination of information (e.g., alert schools in that area to be increasingly vigilant and resources available).

One such tool, Google Analytics (GA) is well positioned to serve those who seek such 'intelligence'. GA (http://www.google.com/analytics), one of the most sophisticated web analytics tools ${ }^{12}$, is a free service that provides detailed information and statistics about website visitors and their activity, such as how far into the website they travel and what links they click on most frequently (useful for search engine optimization). For example, design 
changes based on information compiled from Google Analytics greatly improved the RutgersNewark Law Library for the Center of Law and Justice's website, bringing it more web traffic, greater user loyalty, and more effective navigation ${ }^{13}$.

\section{Aim of the Current Study}

The central aim of the present study was to explore the potential of GA as an effective resource for measuring the impact of academic and practitioner research output. Specifically, the study explored the functionality of GA as a complimentary resource in measuring the impact of the CyberTraining Project by identifying when users were interacting with online resources whilst also identifying the origins of all access. 


\section{METHOD}

One more of most sophisticated aspects of GA V2 is the new immersive data interaction model. The V2 User Interface is completely customizable, ranging from digital dashboards (see Figure 1 below) to overview reports and presentation of the data. Presented in Figure 1 below and in the graphs and statistics that follow are examples of the reports that we used, including site usage / visits, pageviews, bounce rates, average time on site, and the percentage of new visits.

\section{$<$ Insert Figure I here>}

Chronologically, Figure 1 presents the usability data on a monthly basis (also available on a daily and weekly basis). This unique facility allows for comparison of data from different date ranges - e.g., before, during, and after dissemination of the project.

Presented in Figure 2 below is further data intelligence, specifically focused on an overview of site visits. This data provides specific information on usability, such as user loyalty, which includes variables such as the number of visits, unique visitors to the site, and the average time spent on the site by each visit.

$<$ Insert Figure II here>

Figure 3 below provides added insight into the source of all traffic, in terms of direct traffic, referring sites, and search engines. 
Presented in Figure 4 below is further data intelligence which illustrates clearly the sources of all access that is related to the overall visits to the site.

<Insert Figure IV here> 


\title{
RESULTS
}

Table 1 below represents sequential data points across four distinct time frames: (i) 1 month pre-dissemination, (ii) dissemination, (iii) 1 month post-dissemination, and (iv) 3 to 5 month follow-up. Variables monitored included: Visits, Pages Visited, New Visits (\%), Average Time on Site, Absolute Unique Visits, Direct Traffic (\%), Referred Traffic (\%), Search Engines, Primary Sources, Secondary Sources, Top Four Countries, and Top Content.

\author{
<Insert Table I here>
}

\section{Interpretation}

During the pre-dissemination phase, $59.67 \%$ of the 227 visitors to the site during the specified time period were new users. The average time on site was 00:03:40. Usefully, direct traffic (someone entering the specific URL as opposed to using a search engine) to the site was $37.62 \%$ compared to $18.06 \%$ for referred access. Over one-fifth $(22.47 \%)$ of the referred traffic came through Google's search engine. An average of 5.67 pages were visited during each visit. In descending order, the top access countries to the site were: (i) Bulgaria (the web developers), (ii) Germany (project management), (iii) the United Kingdom (UK), and (iv) Switzerland. It would be expected that these figures should increase as information about the CybertTraining website is disseminated across multi-national channels.

During the dissemination phase, 568 people visited the site, an increase of 341 . Twothirds $(66.90 \%)$ of users were new to the site. On average, 2.68 pages were accessed during each visit, with the average time on site reduced to 00:02:17. Direct traffic to the site was $59.03 \%$, with $24.12 \%$ being referred access. In descending order, the top access countries to the site were: (i) Germany, (ii) Italy, (iii) USA, and (iv) Slovakia. As mentioned above, one 
would expect in the future that users would spend more time on the site as a result of additional content.

During the post-dissemination phase, 630 people had visited the site during the specified time period - an increase of 62. Nearly three-quarters of users (71.75\%) were new to the site. On average, 2.88 pages were accessed during each visit, with the average time on site being 00:03:12. Direct traffic to the site was $41.75 \%$ with $22.86 \%$ being referred access. In descending order, the top access countries to the site were: (i) Germany, (ii) the USA (iii) the UK, and (iv) Bulgaria. Again with the addition of new material and the uploading of the complete training manual, one would expect more new users and increased time on site / increased number of pages accessed.

At follow-up, 1,975 people had visited the site during the specified time period $61.37 \%$ of users being new to the site. On average 2.48 pages were accessed during each visit. The average time on site was 00:02:53. Direct traffic to the site was $43.29 \%$, with $33.92 \%$ being referred access. 


\section{DISCUSSION}

The aim of the research was to ascertain the efficacy of Google Analytics (GA) as an effective resource for measuring the impact of the CyberTraining project. As part of the project's dissemination strategy, the eBook was uploaded to the project website in each of the partner country languages. A focused campaign of project dissemination via 'traditional' academic means (e.g., conference presentations, book) promoted the project outside of the partner countries. As noted, such traditional approaches to project dissemination are 'one-way'. With an increasing focus on 'evidence-informed' results, the focus here on using GA to further understand the uptake of the project training manual was positive - especially considering that many of the project team are involved in another EU funded project that builds upon the results of this project (CyberTraining-4-Parents [CT4P]: Project number: 510162-LLP-1-2010-1-DE-GRUNDTVIG-GMP). Similar large-scale multi-partner projects in the area (e.g., COST Action IS0801: http://sites.google.com/site/costis0801) could also benefit from the use of GA in their attempts to influence research, policy, practice, and outcomes.

In essence, GA has demonstrated its worth in assessing the early impact of the CyberTraining project and has allowed for the project team to further understand how best to optimise the 'product' (i.e., the website and the eBook) for ease of access and navigation by unique and referred users. Direct access was, on average $45 \%$, representing 'informed users'. Considering that the content of the eBook was determined by a robust research process, this finding was heartening. Indeed, this figure may also account for informed users who learnt about the project through the traditional means of dissemination also employed. On average, $30 \%$ of new users accessed the website and eBook via Google's search engine - a finding useful for further web optimisation. Such work should evidence an increase in site traffic 
from 'uninformed users' and the 'general public' - a key market for the content of the eBook. In a similar vein, with referred access rates of between $20 \%$ and $25 \%$ from other websites, link-building is an issue that the project team should now also consider. There may also be some potential in developing social networking marketing campaigns (e.g., Facebook).

Such information proves valuable in the iterative development and dissemination of the project and has, directly, informed the planning of the new CT4P project. In terms of cyber-safety, advice for parents ${ }^{14}$ is that: “if you don't understand it, you can't teach it!". The results here from GA further this: if you can't find it, you can't use it! 
DISCLOSURE STATEMENT

No competing financial interests exist. 


\section{REFERENCES}

1. Smith PK, Morita Y, Junger-Tas J, Olweus D, Catalano R, Slee P. (Eds.) (1999). The nature of school bullying: A cross national perspective. London and New York: Routledge.

2. Farrington DP, Ttofi, MM. School-based programs to reduce bullying and victimization. Campbell Systematic Reviews 2009:6, 10.4073/csr.2009.6

3. Smith PK, Pepler DJ, Rigby K. (Eds.) (2004). Bullying in schools: How successful can interventions be? Cambridge: Cambridge University Press.

4. Mc Guckin C, Cummins PK, Lewis CA. f2f and cyberbullying among children in Northern Ireland: Data from the Kids Life and Times surveys. Psychology, Society, \& Education 2010; 2:67-78.

5. Campbell MA Cyber bullying: An old problem in a new guise? Australian Journal of Guidance and Counselling 2005; 15:68-76.

6. Patchin JW, Hinduja S. Bullies move beyond the schoolyard: A preliminary look at cyberbullying. Youth Violence and Juvenile Justice 2006; 4:148-169.

7. Smith PK, Mahdavi J, Carvalho M, Tippett N. (2006) An investigation into cyberbullying, its forms, awareness and impact, and the relationship between age and gender in cyberbullying. Research Brief No. RBX03-06. London: DfES. 
8. Ybarra ML, Mitchell KJ. Prevalence and frequency of internet harassment instigation: Implications for adolescent health. Journal of Adolescent Health 2007; 41:189-195.

9. Ybarra ML, Mitchell KJ. Online aggressor/targets, aggressors, and targets: A comparison of associated youth characteristics. Journal of Child Psychology and Psychiatry 2004; 45:1308-1316.

10. Ybarra ML, Mitchell KJ, Wolak J, Finkelhor D. Examining characteristics and associated distress related to Internet harassment: Findings from the second youth Internet safety survey. Pediatrics 2006; 118:1169-1177.

11. Mora-Merchan, J. Jäger T. (2011) Cyberbullying: A cross-national comparison. Landau: Verlag Emprische Pädagogik.

12. Dyrli OE How effective is your Web site? Free online tools help measure site success. District Administration 2006; 42:72.

13. Fang W Using Google Analytics for improving library website content and design: A case study. Library Philosophy and Practice 2007: June, Special Issue on Libraries and Google.

14. Mc Guckin C, Cummins PK, Lewis CA. New bottle: old wine! Persistence of school bullying among primary school pupils and the emergence of cyberbullying. ARK Research Update 2010; 71. Belfast: ARK 〈http:www.ark.ac.uk/publications/updates/update71.pdf> 
Reprint requests should be directed to:

Conor Mc Guckin

School of Education

Trinity College Dublin

Dublin 2

Ireland

E-mail: conor.mcguckin@tcd.ie 
Figure 1

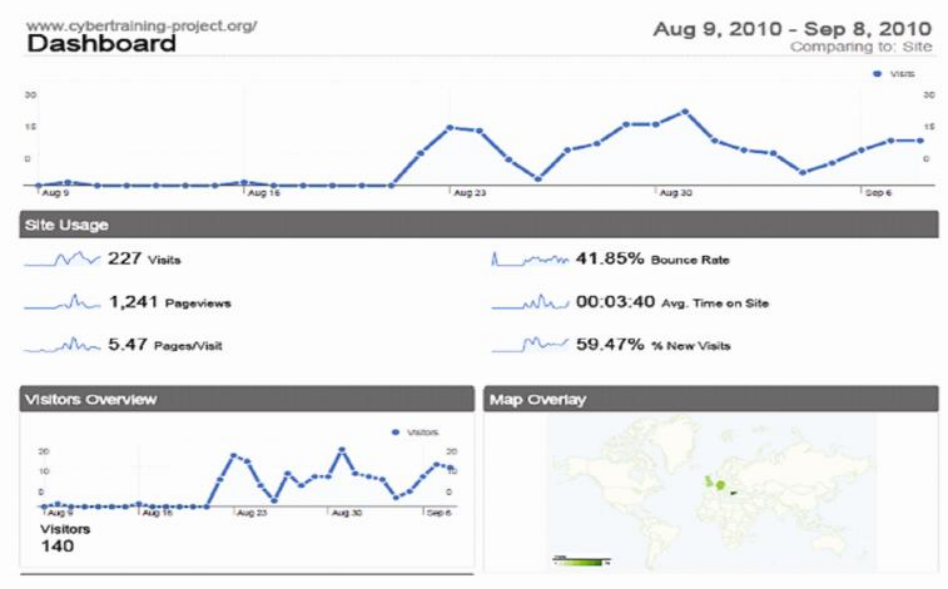


Figure 2

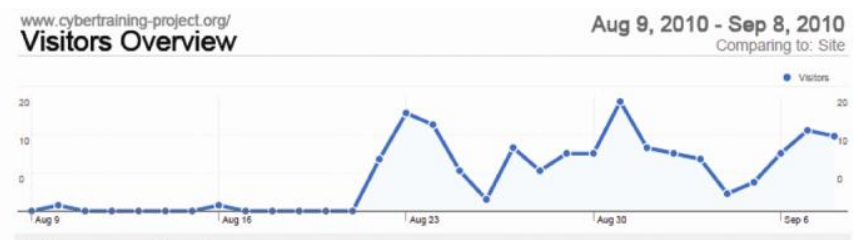

140 people visited this site

$$
\begin{aligned}
& \text { M } 227 \text { visits } \\
& \text { MV } 140 \text { Absolute Unique Vistors } \\
& \text { Ch 1,241 Pageviews } \\
& \text { Whr } 5.47 \text { Average Pageviews } \\
& \text { Whe 00:03:40 Time on Ste } \\
& \text { Lumm 41.85\% Bounce Rate } \\
& \text { Mu } 59.47 \% \text { New Wists }
\end{aligned}
$$




\section{Figure 3}

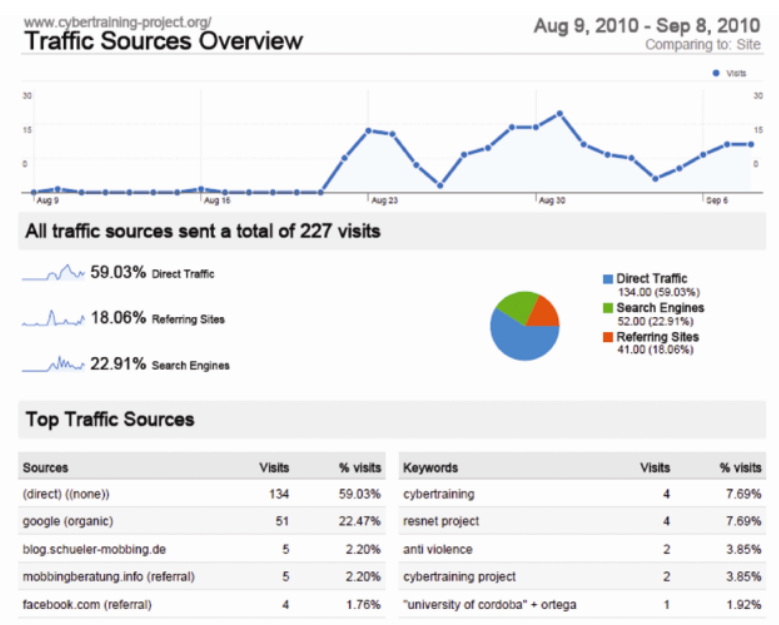


Figure 4

227 visits came from 34 countries/territories

\begin{tabular}{|c|c|c|c|c|c|c|}
\hline \multirow{2}{*}{ 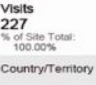 } & \multirow[t]{2}{*}{ 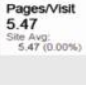 } & \multicolumn{2}{|c|}{ 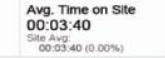 } & \multirow{2}{*}{ 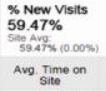 } & \multicolumn{2}{|c|}{$\begin{array}{l}\text { Bounce Rate } \\
41.85 \% \\
\text { Sin. } 45 \% \\
41.05 \%(0.005)\end{array}$} \\
\hline & & vasts & PagesNish & & \& Now Vists & Bounco Rate \\
\hline Bulgaria & & 74 & 10.91 & $\infty 0.07: 42$ & $25.68 \%$ & $29.73 \%$ \\
\hline Germany & & 33 & 3.73 & $000.01: 41$ & 72.736 & $36.36 \%$ \\
\hline United Kingdom & & 23 & 3.48 & $\infty 0.0234$ & 47.836 & $39.13 \%$ \\
\hline Switzertand & & 15 & 2.93 & $\infty 00: 01: 19$ & $80.00 \%$ & $33.33 \%$ \\
\hline siovakia & & ๑ & 4.44 & $\infty 0: 01: 29$ & $55.56 \%$ & 33.336 \\
\hline United States & & 8 & 2.88 & $000: 01: 43$ & $87.50 \%$ & $37.50 \%$ \\
\hline France & & 8 & 1.12 & $00: 00.07$ & $87.50 \%$ & $87.50 \%$ \\
\hline soain & & 6 & 2.87 & $\infty 0.00: 39$ & 83.336 & $50.00 \%$ \\
\hline Romania & & 6 & 2.67 & 00.00 .52 & 100.00\% & 33.336 \\
\hline
\end{tabular}




\section{Table 1}

Table I Chronological Data Captures

\begin{tabular}{|c|c|c|c|c|}
\hline \multirow{2}{*}{ Variable Measured } & Pre-Dissemination & Dissemination & Post- Dissemination & Follow-up \\
\hline & Aug. - Sept. 2010 & Oct. - Nov. 2010 & Nov. - Dec. 2010 & Mar. - May 2011 \\
\hline Visits & 227 & 568 & 630 & 1,975 \\
\hline Pages visited & 5.47 & 2.68 & 2.88 & 2.48 \\
\hline New visits (\%) & 59.47 & 66.90 & 71.75 & 61.37 \\
\hline Avg time on site & $03: 40$ & $02: 17$ & $03: 12$ & $02: 53$ \\
\hline Absolute unique & 140 & 415 & 495 & 1270 \\
\hline \multicolumn{5}{|l|}{ visits } \\
\hline Direct traffic (\%) & 59.03 & 37.62 & 41.75 & 43.29 \\
\hline Referring sites (\%) & 18.06 & 24.12 & 22.86 & 33.92 \\
\hline Search engines (\%) & 22.91 & 38.26 & 35.40 & 22.78 \\
\hline \multirow[t]{2}{*}{ Primary source } & Direct & Search Engines & Direct & Direct \\
\hline & $59.03 \%$ & $38.26 \%$ & $41.75 \%$ & $43.2 \%$ \\
\hline \multirow[t]{2}{*}{ Secondary source } & Google & Direct & Google & Referring Sites \\
\hline & $22.47 \%$ & $37.62 \%$ & $35.40 \%$ & $34.07 \%$ \\
\hline \multirow[t]{4}{*}{ Top 4 countries } & 1. Bulgaria & 1. Germany & 1. Germany & 1. Germany \\
\hline & 2. Germany & 2. Italy & 2. USA & 2. Portugal \\
\hline & 3. UK & 3. USA & 3. UK & 3. USA \\
\hline & 4. Switzerland & 4.Slovakia & 4.Bulgaria & 4. Italy \\
\hline
\end{tabular}

